\title{
Vaccines for human fungal diseases: close but still a long
} way to go

\author{
Lorena V. N. Oliveira $\mathbb{D}^{1}{ }^{1}$, Ruiying Wang $\mathbb{D}^{1}$, Charles A. Specht $\mathbb{D}^{1}$ and Stuart M. Levitz $\mathbb{D}^{1 凶}$
}

Despite the substantial global burden of human fungal infections, there are no approved fungal vaccines to protect at risk individuals. Here, we review the progress that has been made and the challenges that lie ahead in the quest towards efficacious fungal vaccines. In mouse studies, protection has been achieved with vaccines directed against fungal pathogens, including species of Candida, Cryptococcus, and Aspergillus, that most commonly cause life-threatening human disease. Encouraging results have been obtained with vaccines composed of live-attenuated and killed fungi, crude extracts, recombinant subunit formulations, and nucleic acid vaccines. Novel adjuvants that instruct the immune system to mount the types of protective responses needed to fight mycotic infections are under development. Candidate vaccines include those that target common antigens expressed on multiple genera of fungi thereby protecting against a broad range of mycoses. Encouragingly, three vaccines have reached human clinical trials. Still, formidable obstacles must be overcome before we will have fungal vaccines licensed for human use.

npj Vaccines (2021)6:33; https://doi.org/10.1038/s41541-021-00294-8

\section{INTRODUCTION}

The global burden of serious fungal diseases is increasing as a direct consequence of the burgeoning number of immunocompromised persons ${ }^{1}$. Risk factors for invasive fungal infections include infection with the human immunodeficiency virus (HIV), immunosuppressive therapy to prevent organ transplant rejection, biological immunomodulatory agents to treat autoimmune diseases, bone marrow suppressing cancer chemotherapies, indwelling devices such as intravenous catheters, and long-term hospitalization, especially with receipt of broad-spectrum antibiotics ${ }^{1,2}$. Even with the availability of antifungal drugs, the burden of life-threatening fungal infections is thought to exceed one million deaths annually, although numbers are difficult to estimate due in part to inadequate availability of diagnostic tests and disease reporting ${ }^{3,4}$. Superficial mycoses, such as dermatophytic infections of the skin and nails, affect more than $25 \%$ of the population worldwide, although they are generally treatable ${ }^{3}$. The annual medical cost of fungal diseases is estimated to exceed 7.2 billion dollars in the United States alone ${ }^{5}$.

The substantial morbidity and mortality rates highlight the relevance of developing effective vaccines to control fungal pathogens. Despite efforts, unfortunately, there are no licensed vaccines available to prevent and control human invasive fungal infections. In this review, we outline the advances and challenges toward the development of fungal vaccines, providing examples of potential targets and promising vaccine strategies.

\section{Challenges and efforts toward developing fungal vaccines}

Vaccines are considered one of the greatest achievements in medicine $^{6}$. For example, their use led to eradication of smallpox, and substantially reduced poliomyelitis, measles, diphtheria, and pneumococcal infections ${ }^{7}$. Additionally, according to the World Health Organization (WHO), vaccines are being successfully used against more than 25 debilitating or life-threatening diseases, including tetanus, rabies, influenza, meningitis, cholera, rubella, and hepatitis $B$.
For protection against communicable diseases, vaccines are among the most cost-effective measures available. Vaccines for many infectious diseases, including invasive mycoses, however, are not available ${ }^{6,8}$. Fungal diseases often have a poor prognosis stemming in part from the limited arsenal of antifungal drugs compounded by the increasing occurrence of antifungal resistance ${ }^{9}$. The lack of reliable diagnostics for many fungal diseases can lead to delays in treatment ${ }^{3}$. Given that, worldwide efforts are being made to develop vaccines against fungal pathogens $s^{2,8,10,11}$. Still, formidable challenges remain, many of which, along with their potential solutions, are listed in Table 1.

As mentioned, the immunocompromised population is at highest risk for serious fungal infections. However, immunological impairment poses challenges with respect to both the efficacy and safety of vaccines. In this regard, the high immunogenicity of live vaccines makes them perhaps most likely to elicit protective responses, but must be used with caution because of the potential risk for infections from the vaccine itself. On the other hand, inactivated whole organism and subunit vaccines are safer; however, immunocompromised individuals are less likely to respond to vaccination due to their debilitated immune status ${ }^{12}$. Efforts are being made to improve adjuvants and vaccine formulations to elicit stronger protective responses, and to target those immune response pathways that may not be compromised $^{6}$. Another potential solution is vaccinating individuals prior to their anticipated immunosuppression when the immune system is still functionally effective. Examples include persons awaiting solid organ transplantation and individuals with HIV infection, who have relatively high $\mathrm{CD} 4^{+} \mathrm{T}$ cell counts.

An additional challenge to developing a vaccine is translating preclinical studies in animals to humans. Most in vivo vaccine studies are initially conducted in inbred mice, as they are relatively inexpensive and have a well-defined immune system. However, inherent differences in murine and human immune responses are still a concern and caution needs to be taken with regard to extrapolating efficacy data across species ${ }^{13}$. Even with the attempt to reproduce aspects of human disease, inbred mice lack genetic

\footnotetext{
${ }^{1}$ Department of Medicine, University of Massachusetts Medical School, Worcester, MA, USA. ${ }^{{ }^{*}}$ email: stuart.levitz@umassmed.edu
} 
Table 1. Challenges associated with fungal vaccine development.

\begin{tabular}{|ll}
\hline Challenges & Potential solutions \\
\hline Population most at risk is immunosuppressed & Vaccinate prior to anticipated immunosuppression. \\
& $\begin{array}{l}\text { Augment specific immune system responses less affected by immunosuppression. } \\
\text { Transfer protective lymphocytes to patient. } \\
\text { Improve adjuvants. }\end{array}$ \\
$\begin{array}{ll}\text { Diverse infection sites in the host } & \text { Utilize delivery systems or adjuvants that drive the immune response at multiple sites of } \\
\text { infections. }\end{array}$ \\
$\begin{array}{ll}\text { Intraspecies and interspecies antigenic variation } \\
\text { among fungi }\end{array}$ & $\begin{array}{l}\text { Target multiple epitopes with multivalent vaccines. } \\
\text { Similarities between Fungi and Animalia kingdoms }\end{array}$ \\
$\begin{array}{ll}\text { Translation from animal models to humans } \\
\text { Formulation }\end{array}$ & $\begin{array}{l}\text { Use protein antigens unique to fungi to minimize autoimmune responses. } \\
\text { Test the candidate vaccine in multiple animal models. }\end{array}$ \\
Commercialization & $\begin{array}{l}\text { Perform ex vivo studies with human cells. } \\
\text { Select a delivery system and/or adjuvants to optimize protective responses and safety. }\end{array}$ \\
& $\begin{array}{l}\text { Attract interest and investments from governmental agencies, non-governmental } \\
\text { organizations, and biopharmaceutical companies. }\end{array}$
\end{tabular}

Table 2. Major components of fungal cell walls.

\begin{tabular}{|c|c|c|}
\hline $\begin{array}{l}\text { Fungal cell wall } \\
\text { components }\end{array}$ & Structure composition & Location \\
\hline Chitin & Homopolymer of N-Acetylglucosamine that provides structural stability & $\begin{array}{l}\text { Inner portion of cell wall, adjacent to the } \\
\text { plasma membrane }\end{array}$ \\
\hline Chitosan & Deacetylated chitin & $\begin{array}{l}\text { Inner portion of cell wall, intermingled } \\
\text { with chitin }\end{array}$ \\
\hline$\beta$-glucan & $\begin{array}{l}\text { Homopolymers of glucose with } \beta-1,3 \text {-glucans forming the scaffold and } \\
\beta-1,6 \text {-glucans forming the branches }\end{array}$ & $\begin{array}{l}\text { Middle portion of cell wall, between chitin } \\
\text { and mannans }\end{array}$ \\
\hline
\end{tabular}

diversity. Moreover, laboratory mice are generally housed under conditions whereby they have limited exposure to environmental fungi, such as airborne spores and thus may not be exposed to fungal antigens commonly encountered in the "real world". To minimize these drawbacks, prior to clinical studies, vaccine candidates ideally should be tested in multiple animal models.

Reactogenicity and safety must be investigated in pre-clinical models as a prerequisite to clinical trials ${ }^{14}$. At this point, converting a vaccine candidate into one approved for use in humans entails financing clinical trials and product manufacture. For those fungal infections that mostly affect populations living in resource-limited areas, the interest of pharmaceutical companies may be limited and vaccine commercialization could require attracting investments of governmental and non-governmental organizations ${ }^{11}$. That said, fungal pathogens are a major public health concern worthy of global attention, and funding incentives for preventive fungal vaccines are urgently needed.

\section{Fungal cell wall structure}

Fungi and animals are phylogenetically grouped in the same Eukaryotic domain ${ }^{15}$. Then not surprisingly, many similarities exist between fungal and human cells; these become important considerations for drug discovery and treatment of fungal diseases. A major difference between the Fungi and Animalia kingdoms is the presence of the cell wall on almost all fungal cells ${ }^{16}$. Consequently, the proteins that synthesize and remodel the cell wall are important drug targets. Moreover, fungal cell wall components are recognized by the innate immune system in humans ${ }^{17,18}$, leading to adaptive and trained immune responses.
As discussed below, an area of research is exploiting this response in vaccine development.

The cell wall is composed mainly of conserved crosslinked carbohydrate polymers and mannoproteins that are recognized by pattern recognition receptors on immune cells of the host, notably monocytes, macrophages, and dendritic cells ${ }^{19,20}$. The most abundant components of the fungal cell wall are mannoproteins and $\beta$-glucans, followed by chitin/chitosan. Mannoproteins are predominately found in the outer portion of cell wall, $\beta$-glucans tends to be in the middle, while chitin/chitosan trends towards the inner portion of the cell wall. These constituents of the cell wall are found in practically all invasive fungal pathogens (reviewed in the refs. ${ }^{18,21}$ ). An overview of the fungal cell wall components is provided in Table 2 and Fig. 1.

Some fungal cell walls also contain galactomannan, a-glucan and melanin ${ }^{21}$. In addition, it is important to highlight the presence of a polysaccharide capsule on Cryptococcus spp., composed primarily of glucuronoxylomannan (GXM) and galactoxylomannan; the capsule is a dominant virulence factor ${ }^{22}$. Structurally, the capsule envelops the cell wall and, among its several roles, "masks" recognition of cell wall ligands by pattern recognition receptors thus interfering with the development of immunity ${ }^{16}$. Finally, fungi release extracellular vesicles containing proteins, lipids, and nucleic acids. In addition to secretion into the extracellular milieu, extracellular vesicles may traffic to the cell wall and contribute to cell wall remodeling and enable surface expression of proteins ${ }^{23}$.

Compounding the challenges encountered by interspecies differences in the fungal cell wall structure, the host faces dynamic changes in the distribution and amount of fungal cell 
wall components that accompany morphological changes during infection. External stress events, transition between yeast and hyphal growth, and the process of cellular division can impact the cell wall to decrease host recognition, impair inflammatory responses, and increase fungal virulence ${ }^{16,24}$.

\section{Fungal vaccine categories and adjuvants}

Fungal vaccines can be divided into several broad categories based upon their composition, ranging from multiple to single antigens: whole organism vaccines (live-attenuated or killed fungal cells), crude extracts (fractions derived from cells and medium of fungal cultures), purified subunit vaccines (proteins, peptides), and nucleic acids (RNA and DNA) encoding the antigen(s) of interest (Table 3). Approaches using dendritic cells pulsed ex vivo with antigen(s) are not practical for routine immunizations, but have potential for use in therapeutic vaccines for patients with refractory diseases ${ }^{25}$. As discussed above, whole organism vaccines generally have strong immunogenicity but often at the cost of increased side effects, including risk of infection when live-attenuated vaccines are given to immunocompromised populations. Thus, many investigators have focused on identifying antigens which, either in native or recombinant form, can be used in subunit fungal vaccines.

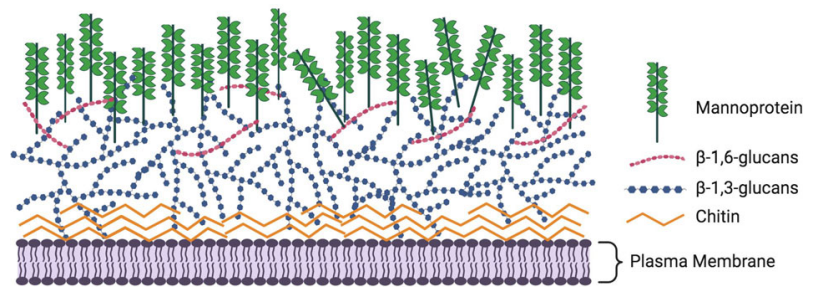

Fig. 1 Schematic model of the fungal cell wall. This model shows the three basic components of the cell wall present in almost all fungal pathogens. Mannoproteins have polymers of mannose that decorate the proteins through O-linkages or $\mathrm{N}$-linkages and are predominately found in the outer portion of cell wall. $\beta$-glucans are the most abundant constituent of the cell wall and tend to be in the middle with $\beta-1,3-$ glucans forming the scaffold and $\beta-1,6-$ glucans forming the branches, while chitin is found in the inner portion of the cell wall and linked to $\beta-1,3-$ glucan. Other components of the cell wall in some fungi include $\alpha$-glucan, galactomannan, chitosan, and melanin. In addition, the cryptococcal capsule is linked to the cell wall. Figure created with BioRender.com.
Subunit vaccines require adjuvants, compounds which enhance antigen immunogenicity by promoting adaptive immune responses. Most vaccines in clinical use mediate antibodydependent protection via mechanisms that include opsonophagocytosis and neutralization of viruses and toxins. Traditional adjuvants which promote antibody responses, particularly alum, have been effective for these purposes. However, because $\mathrm{CD} 4^{+} \mathrm{T}$ helper cell (Th)-mediated immunity is paramount for defending against many mycoses, adjuvants which elicit strong Th1 or Th17 cell-mediated responses have been proposed for inclusion in fungal vaccines ${ }^{26}$. Some adjuvants used in experimental models to stimulate Th responses, such as complete Freunds adjuvant, are too toxic for routine use in humans but may be useful in experimental vaccine studies to demonstrate proof of principle ${ }^{27}$. Other adjuvants, such as CpG oligodeoxynucleotides, may be more translationally relevant as they have been used in human vaccines ${ }^{6}$.

We and others have proposed exploiting components of fungal cell walls, such as $\beta-1,3$-glucans and mannans, as adjuvants, reasoning that the immune response generated will mimic the type of protective immune response seen in natural infection ${ }^{18}$. One such approach has been to package fungal antigens into glucan particles (GPs). GPs are hollow, porous yeast cell wall shells manufactured from Saccharomyces cerevisiae, and primarily composed of $\beta-1,3$-glucan ${ }^{28}$. GPs are recognized by Dectin- 1 and are also potent activators of the complement pathway ${ }^{29}$. Mice immunized with GPs loaded with the model antigen ovalbumin developed long-lasting antigen-specific antibody and Th1-biased and Th17-biased $\mathrm{CD}^{+} \mathrm{T}$ cell responses ${ }^{28}$. Mice vaccinated with GPs formulated with fungal antigens were protected following challenges with a range of fungal pathogens ${ }^{30-33}$. Using a related approach, protective vaccines consisting of Coccidioides and Blastomyces antigens packaged into glucan-chitin particles (GCP) have been described ${ }^{34}$. GCPs are similar to GPs except they are produced from the yeast Rhodotorula mucilaginosa and contain extra chitin in their cell walls.

\section{Potential fungal vaccines}

Candida, Cryptococcus, Aspergillus, and Pneumocystis are the most common fungal genera causing invasive human infections. Endemic dimorphic fungi, such as Histoplasma, Coccidioides, Paracoccidioides, and Blastomyces also cause invasive mycosis ${ }^{1-3}$. Examples of the disparate morphologies of fungi in human tissue are shown in Fig. 2. Other fungi that cause serious infections include species of Mucor, Sporothrix, Scedosporium, and Fusarium ${ }^{1}$.

Table 3. Overview of the advantages and disadvantages of the major fungal vaccine categories.

\begin{tabular}{|c|c|c|c|}
\hline Vaccine Category & Advantages & Disadvantages & Representative vaccines \\
\hline Live-attenuated & $\begin{array}{l}\text { Strong and long-lasting } \\
\text { immunogenicity; manufacturing } \\
\text { processes are straightforward }\end{array}$ & $\begin{array}{l}\text { Risk of sustained infection in } \\
\text { immunocompromised population; } \\
\text { reactogenicity; autoimmunity }\end{array}$ & $\begin{array}{l}\text { Mutant } C \text {. neoformans strain lacking } \\
\text { the enzyme sterylglucosidase } 1^{59}\end{array}$ \\
\hline Killed fungus & $\begin{array}{l}\text { Cannot cause infection; stabler } \\
\text { than live-attenuated vaccines; } \\
\text { manufacturing processes are } \\
\text { straightforward }\end{array}$ & $\begin{array}{l}\text { Elicit less strong immune responses } \\
\text { compared to live vaccines; reactogenicity; } \\
\text { autoimmunity }\end{array}$ & $\begin{array}{l}\text { Formalin-killed spherule vaccine for } \\
\text { coccidioidomycosis }^{75}\end{array}$ \\
\hline Fungal extracts & $\begin{array}{l}\text { Contain numerous multivalent } \\
\text { antigens }\end{array}$ & Reactogenicity; autoimmunity & $\begin{array}{l}\text { Glucan particles containing } \\
\text { Cryptococcus alkaline extracts }\end{array}$ \\
\hline $\begin{array}{l}\text { Purified proteins, } \\
\text { peptides, carbohydrates, } \\
\text { and lipids }\end{array}$ & $\begin{array}{l}\text { Fewer antigens minimizes the } \\
\text { potential side effects }\end{array}$ & $\begin{array}{l}\text { Narrow immune response due to fewer } \\
\text { antigens; adjuvants are needed; careful } \\
\text { epitope selection, antigen design and } \\
\text { purification are required }\end{array}$ & $\begin{array}{l}\text { NDV-3A vaccine (containing the } \\
\text { recombinant N-terminus of C. albicans } \\
\text { agglutinin-like sequence } 3 \text { protein) }\end{array}$ \\
\hline $\begin{array}{l}\text { Nucleic acid-encoded } \\
\text { delivery of antigen(s): } \\
\text { DNA or RNA vaccine }\end{array}$ & $\begin{array}{l}\text { Fast manufacturing process; } \\
\text { strong immune responses }\end{array}$ & $\begin{array}{l}\text { Risks of eliciting unintended immune } \\
\text { reactions; strict temperature requirements for } \\
\text { storage }\end{array}$ & $\begin{array}{l}\text { DNA vaccine encoding cell wall } \\
\text { antigen Mp1p against Penicillium } \\
\text { marneffei infection } 81\end{array}$ \\
\hline
\end{tabular}




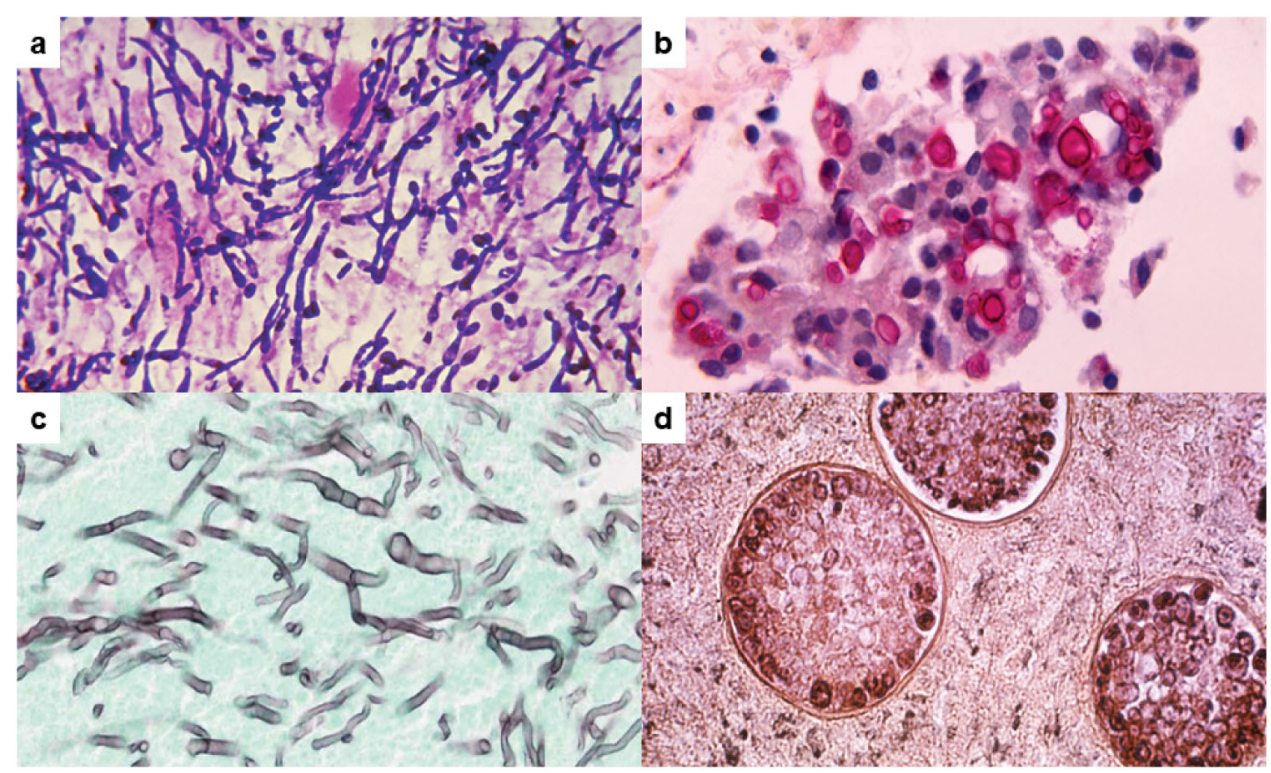

Fig. 2 Examples of the diversity in fungal morphology in human tissue from patients with mycoses. a Tissue Gram stain of $C$. albicans from a patient with endocarditis. Hyphae (elongated cells), pseudo-hyphae (sausage-shaped cells) and yeasts (oval cells, some with buds) stain deep purple. Candida cells average 2-8 microns in diameter. b Mucicarmine stain of C. neoformans in the lungs of a patient with pulmonary cryptococcosis. Budding yeast cells with capsules that stain rose red are present. Yeast cells average about 5 microns in diameter without capsule. Capsular thickness is variable, typically ranging from 1 to 10 microns. c Grocott's methenamine silver stain of $A$. fumigatus from a patient with invasive pulmonary aspergillosis. Septate hyphae with " $Y$ "-shaped branching that stain silvery black are present. Average hyphal diameter is about 3 microns. d Periodic acid-Schiff stain of $C$. immitis from a patient with coccidioidomycosis. Three spherules, each containing endospores, are present. Spherules and endospores range in diameter from 10 to 100 microns and 2 to 5 microns, respectively. A single spherule can contain hundreds of endospores. Photo image credits. a, b, and d: Centers for Disease Control Public Health Image Library. c: Wikimedia Commons.

However, for these and other relatively rare fungi, clinical testing of pathogen-specific vaccines presents obvious logistical difficulties. In this section, we review vaccine candidates against the fungal genera responsible for most cases of invasive mycoses.

\section{Candida sp.}

Candida species commonly colonize humans as commensal organisms; however, in situations of immunosuppression they can opportunistically become pathogens. Candida albicans and non-albicans species are the most common cause of lifethreatening invasive fungal infections $s^{9,35}$. Globally, an estimated 700,000 persons a year suffer from invasive candidiasis ${ }^{4}$, with an associated mortality that may exceed $50 \%^{3}$. Furthermore, Candida can also cause mucocutaneous infections, such as vulvovaginal candidiasis which, while rarely lethal, are associated with significant morbidity ${ }^{9}$. For example, vulvovaginal candidiasis can have a profoundly negative impact on quality-of-life. It is estimated that the majority of women experience vulvovaginal candidiasis at least once in their lifetime and many women suffer from recurrent disease ${ }^{36}$. Importantly, the emergence of drug resistant strains, such as $C$. auris, is a public health concern. Thus, the need for new therapies and protective vaccines against Candida has increased.

With mouse models of vulvovaginal and/or systemic candidiasis, the efficacy of anti-Candida vaccines has been demonstrated targeting virulence factors, and Candida virulent forms such as hyphae and cell wall antigens, with a variety of formulations, including live attenuated (generally strains with impaired yeasthyphae conversion ${ }^{37}$ ); recombinant proteins (using surfacelocated or adhesion proteins ${ }^{38,39}$ ); cell wall extracts, extracellular vesicles $^{40}$, and glycoconjugates ${ }^{41}$. However, morphological, phenotypic, and genetic variability among Candida species poses a challenge to vaccine development. In addition, as Candida is a common human commensal, there is a theoretical concern that
Candida vaccines could disrupt the normal microbiota. Targeting antigens specific to the invasive hyphal form could minimize this potential drawback. On the host side, the diverse infection sites and the different kinds of immune deficiencies in at-risk groups are obstacles for designing a vaccine that broadly protects this wide clinical spectrum of disease?.

Two recombinant Candida vaccines have reached human clinical testing with promising results. The first, named PEV7, consists of recombinant aspartyl-proteinase 2 (Sap2), a secreted protein of C. albicans, assembled into virosomes ${ }^{38,42}$. After protection was demonstrated in C. albicans-challenged rats, a phase 1 clinical trial was conducted to assess the safety and immunogenicity of PEV7 in healthy female volunteers. All of the 48 vaccinated women developed specific B-cell memory responses (ClinicalTrials.gov identifier: NCT01067131) ${ }^{38}$.

The second vaccine, NDV-3, contains the recombinant $\mathrm{N}$ terminus of $C$. albicans agglutinin-like sequence 3 protein (Als3p, a cell surface adhesin and invasin) formulated with aluminum hydroxide adjuvant ${ }^{39,43}$. Preclinical studies demonstrated the vaccine was immunogenic and protected mice from Candida species. Interestingly, mice were also protected following challenge with Staphylococcus aureus, apparently due to structural homology between Als $3 p$ and surface proteins on $S$. aureus. In a phase 1 clinical trial which recruited 40 volunteers, NDV-3 elicited increased antigen-specific lgG and IgA1 titers as well as increased IFN- $\gamma$ and IL-17A cytokine production compared to placebo recipients (ClinicalTrials.gov identifier: NCT01273922) ${ }^{39}$. Based on these data and a favorable safety profile, a multicenter doubleblind placebo-controlled phase $1 \mathrm{~b} / 2 \mathrm{a}$ trial was undertaken to assess the immunogenicity and efficacy of the NDV-3A vaccine in 188 women with recurrent vulvovaginal candidiasis (RVVC $)^{43}$. NDV-3A is identical to NDV-3 except it lacks a 6-His tag and linker sequences. As with NDV-3, NDV-3A was safe and highly immunogenic. There were no statistically significant differences between treatment and placebo groups in the primary efficacy 
analysis. However, in a post-hoc subgroup analysis, subjects aged $<40$ years had significantly fewer RVVC episodes during the 12month study period (ClinicalTrials.gov identifier: NCT01926028) ${ }^{43}$.

Women with RVVC represent a logical population for Candida vaccine studies because the incidence of recurrence is high and therefore vaccine efficacy can be determined without having to enroll inordinately large numbers of subjects in clinical trials. But it should be appreciated that in many women, RVVC is thought to be due to an overly exuberant inflammatory response to Candida and therefore therapeutic vaccines have the potential to worsen disease ${ }^{44}$. Studies to determine whether vaccines can prevent invasive candidiasis would likely need to enroll thousands of patients given the relatively low incidence even in the higher risk populations.

PEV7 and NDV-3A vaccines each were formulated with a single protein antigen. Given intraspecies and interspecies antigenic variation, including differences between yeast and hyphal forms, many investigators aim to develop multivalent Candida vaccines that would provide enhanced protection. This tactic has the potential to expand the protective range of the immune response, while decreasing the ability of Candida to evade host immunity ${ }^{45}$. Approaches include combining known immunogenic antigens and using in silico analysis to identify immunodominant Candida antigens ${ }^{45,46}$.

\section{Cryptococcus sp.}

The species complexes of Cryptococcus neoformans and C. gattii cause cryptococcosis. Infection is thought to most commonly start after pulmonary inhalation; subsequent dissemination to other organ systems, particularly the central nervous system, can ensue. Persons with compromised $\mathrm{T}$ cell immunity are particularly susceptible. Annually, more than 220,000 cryptococcal meningitis cases in HIV-infected persons are estimated to occur worldwide, with about 180,000 deaths ${ }^{47}$. Cryptococcus is unique among the medically important fungi in being encapsulated; this presents opportunities and challenges in terms of vaccine development. Its polysaccharide capsule, which consists mainly of GXM, is poorly immunogenic. To improve the antigenicity of GXM, a vaccine containing GXM conjugated to tetanus toxoid was developed; immunized mice developed antibodies against GXM and were partially protected following challenge with C. neoformans ${ }^{48}$. Similarly, a conjugated peptide mimetic of GXM elicited protective antibodies ${ }^{49}$.

Other groups have focused on discovering protein antigens that stimulate $T$ cell responses for inclusion in subunit vaccines. Vaccines containing crude fractions isolated from acapsular and encapsulated cryptococcal strains by a variety of techniques, including concanavalin A binding (to enrich for mannoproteins) ${ }^{50}$ molecular sizing ${ }^{51}$, alkaline extraction ${ }^{52}$, cellular fractionation ${ }^{53}$, and purification of extracellular vesicles ${ }^{54}$, provided some degree of protection against challenge with $C$. neoformans and C. gattii. More recent work has sought to discover individual antigenic proteins which protect in mouse models of cryptococcosis. Using biased and unbiased selection, our laboratory has identified 11 proteins which, when recombinantly expressed and delivered in glucan particles, protect BALB/c and/or C57BL/6 mice against an otherwise lethal infection ${ }^{32,55}$.

Several live-attenuated and heat-killed cryptococcal mutant strains have been proposed as vaccine candidates based on encouraging protection data. Pulmonary administration of an avirulent chitosan-deficient strain, constructed by deleting three chitin deacetylase genes, conferred full protection against a subsequent $C$. neoformans lethal infection. The vaccine elicited a protective Th1-type adaptive immune response and was effective even when heat-killed ${ }^{56}$. Mice were also protected from otherwise lethal challenge with mutant $C$. neoformans vaccine strains: 1 ) overexpressing the transcription factor, $\mathrm{Znf} 2^{57} ; 2$ ) lacking sterylglucosidase, which results in accumulation of the glycolipid, sterylglucoside, in the cell membrane ${ }^{58}$; and 3) lacking the F-box protein $\mathrm{Fbp}^{59}$.

Two whole organism Cryptococcus vaccine approaches that provide proofs of principle, albeit with limited direct translation relevance, are worth noting. In the first, a $C$. neoformans strain was genetically engineered to express murine IFN- $\gamma$. Mice vaccinated with this strain were fully protected from subsequent challenge with a highly virulent strain by mechanisms dependent on STAT1 signaling and induction of trained immunity of dendritic cells $^{60,61}$. In the second approach, bone marrow-derived dendritic cells were pulsed with heat-killed acapsular $C$. gattii cells and then injected intravenously into mice. The vaccine induced lungresident memory Th17 cells and conferred protection upon recipient mice challenged with a virulent C. gattii strain ${ }^{25}$.

Finally, although closely related, the species complexes of C. neoformans and C. gattii cause infections with distinct clinical manifestations. The species elicit divergent immune responses ${ }^{62}$ and differ in terms of the proteome expressed during infection. Ideally, candidate vaccines able to protect against both species should be prioritized for advancement to human testing. However, for areas such as British Columbia, Canada, where hypervirulent strains of $C$. gattii are endemic, it may be practical to develop a species-specific vaccine to protect the population.

\section{Aspergillus sp.}

Aspergillus is a globally ubiquitous filamentous fungus, widely present in soil and decaying vegetation. Airborne spores (conidia) are regularly inhaled and are typically contained by host defenses without being harmful. However, in at risk immunosuppressed individuals, germination of conidia into tissue invasive hyphae can cause a range of acute to chronic diseases. Persons most at risk include those with neutropenia, recipients of stem cell and solid organ transplants, and those receiving immunosuppressive therapy such as corticosteroids ${ }^{11,63}$. Essentially, these conditions pose a challenge to develop a vaccine for this target population given that the protective immunity may be diminished, together with the fact that the host needs to recognize and fight against different structures of the fungi, such as, conidia, germ tubes, and hyphae. A. fumigatus is the most prevalent species of Aspergillus responsible for opportunistic human infections, although other species, most commonly A. flavus, A. niger, A. terreus, and $A$. nidulans, can also cause disease ${ }^{63}$. Invasive aspergillosis is responsible for over 200,000 cases annually and associated with a high mortality rate. Furthermore, allergic manifestations can occur with sensitization to Aspergillus allergens, generally in patients with cystic fibrosis, severe asthma with fungal sensitization and allergic bronchopulmonary aspergillosis, the latter alone is thought to affect around 5 million people ${ }^{3,63}$. Therapeutic vaccines to mitigate the allergic response and bias immunity towards protective responses have promise for these difficult to treat diseases, but are still in the early development stage. Another potential Aspergillus vaccine market targets avian aspergillosis; outbreaks in commercial poultry flocks, particularly turkeys, can have major economic consequences ${ }^{64}$.

Vaccination studies in mice have demonstrated protection using crude and recombinant Aspergillus antigens delivered using a variety of routes and adjuvants (reviewed in the ref. ${ }^{65}$ ). When examined, protection generally required $\mathrm{CD}^{+}{ }^{+} \mathrm{T}$ cells. Dendritic cells pulsed with conidia or conidial RNA also conferred Th1mediated antifungal resistance in a mouse model of allogeneic hematopoietic transplantation ${ }^{66}$. These studies informed innovative studies in humans undergoing allogenic hematopoietic transplant, where donor $T$ cells can be expanded ex vivo with Aspergillus antigens and adoptively transferred into the patient. Aspergillus-specific $\mathrm{CD}^{+}$and IFN- $\gamma$-producing $\mathrm{T}$ cell clones, generated by incubating peripheral blood mononuclear cells with 
heat-killed conidia, were adoptively transferred to transplant recipients with evidence of invasive aspergillosis. Encouragingly, 9 of 10 patients who received adoptive T cells resolved their infection, compared to 7 of 13 control patients who did not receive the immunotherapy ${ }^{67}$. A more efficient method for ex vivo expansion of donor T-cell populations using recombinant $A$. fumigatus proteins and selection based on expression of the activation markers CD154 and CD137 has been described ${ }^{68}$. Crossreactivity to other species was observed suggesting this could be part of a broad approach towards therapeutic vaccination in immunocompromised patients with mold infections ${ }^{68}$. Another novel approach worthy of mention, although not technically a therapeutic vaccine, is the use of chimeric antigen receptor (CAR) $\mathrm{T}$ cells genetically modified for fungal specificity. CAR T cells expressing the $\beta-1,3-$ glucan receptor Dectin-1 bound to and inhibited $A$. fumigatus ${ }^{69}$.

The above studies looked at vaccines that protected largely by eliciting T cell-mediated immunity. Surprisingly, few studies have focused on vaccines designed to elicit protective antibodies. That this approach has merit is suggested by studies showing extended survival of mice that received passive administration of monoclonal antibodies directed to cell surface antigens of $A$. fumigatus ${ }^{65,70}$. In accordance, exploiting an observation that some sialylated oligosaccharide structures are present in both group $B$ Streptococcus (GBS) and A. fumigatus, passive transfer of a GBSspecific monoclonal antibodies, and vaccination with GBS improved survival in mouse models of invasive aspergillosis ${ }^{71}$.

\section{Endemic mycoses}

Endemic mycoses are caused by dimorphic fungi of the Ascomycota phylum, including species of Histoplasma, Coccidioides, Blastomyces, Paracoccidioides, Talaromyces, and Emergomyces. After infectious spores encounter mammalian hosts, temperature-induced phase transition to tissue-invasive yeasts, or for Coccidioides, spherules, occurs ${ }^{72}$. Three factors make the endemic mycoses attractive candidates for vaccine development. First, they cause significant morbidity in apparently immunocompetent individuals. Second, a vaccine could be targeted to those at risk due to residence in or travel to the geographic areas where the mycosis is found. Third, the causative fungi are genetically related which increases the feasibility of developing crossprotective vaccines.

A formalin-killed spherule (FKS) vaccine for coccidioidomycosis was studied in a human clinical trial after it showed promising results in mice and Rhesus monkeys. A Phase 3 study randomized 2867 healthy volunteers from California and Arizona; groups received three intramuscular injections of either FKS vaccine or sterile $\mathrm{NaCl}$ solution. Unfortunately, no significant differences were observed between groups in terms of clinical endpoints, and the vaccinated groups had greater local and systemic adverse reactions ${ }^{73}$. Nevertheless, the study demonstrated the feasibility of conducting human trials of fungal vaccines. In the field of veterinary medicine, a genetically engineered live-attenuated strain of $B$. dermatitidis, lacking the major virulence factor BAD-1, was safe, well-tolerated, and immunogenic in dogs ${ }^{74}$. Studies to determine vaccine efficacy in canine blastomycosis are still needed, although in experimental models, the vaccine did protect mice from lethal infection.

Given their theoretical safety advantages, identification of protective antigens for use in subunit vaccines has been the focus of much research. One of the earliest candidate antigens identified was heat shock protein (Hsp) 60. Vaccination with recombinant $\mathrm{Hsp60}$ induced protective immunity against Histoplasma and Paracoccidioides following pulmonary infection in mice $^{75,76}$. Fungal and mammalian $\mathrm{Hsp}$ are evolutionarily conserved; this raises theoretical concerns about untoward autoimmune responses unless homologous regions are edited out.
Other recombinant antigens, many of which have no significant human homologies, have protected mice in experimental models of endemic mycoses ${ }^{77-79}$. A multivalent vaccine containing three recombinant antigens elicited protective responses in mice challenged with Coccidioides ${ }^{80}$. Moreover, when the peptides of these proteins that elicited the best $T$ cell responses were combined into a recombinant epitope-based vaccine, enhanced survival, reduced fungal burden, and robust Th1 and Th17 immune responses were observed ${ }^{81}$. Use of chimeric proteins reduces the expense of manufacturing and testing vaccines, but could generate unwanted immune responses to the created neoantigens.

\section{Pan-fungal vaccines}

The above vaccine strategies are mainly focused on preventing specific mycoses. The "holy grail" is a pan-fungal vaccine that protects against many if not most of the broad range of systemic fungal infections seen in the human population. In this regard, several vaccine candidates are worthy of mention. As noted above, nearly all medically important fungi possess a cell wall that contains $\beta$-glucans. Immunization of mice with $\beta$-glucans conjugated to the carrier protein CRM197 resulted in protection against challenge with taxonomically distant fungal pathogens, including C. albicans, A. fumigatus, and C. neoformans ${ }^{82,83}$. Protection was correlated with an antibody response directed against $\beta$-1,3-glucan, but not $\beta-1,6$-glucan ${ }^{84}$. Similarly, mice given a subcutaneous inoculation containing whole heat-killed Saccharomyces cerevisiae yeast cells were protected against a subsequent challenge with fungi from five genera; the mechanism is uncertain but postulated to require $\mathrm{T}$-cell adaptive responses ${ }^{85,86}$. Mice vaccinated with the aforementioned $C$. neoformans strain deleted of the F-box protein $\mathrm{Fbp}^{59}$ are cross-protected against C. gattii, Aspergillus fumigatus, and Candida albicans, suggesting its potential to act as a pan-fungal vaccine ${ }^{59}$.

Interestingly, $\beta$-glucans are strong stimulators of "trained immunity", a process whereby activation of innate immunity leads to epigenetic changes that enhance responses to subsequent infections ${ }^{87}$. The contribution of trained immunity to the cross-protection seen with pan-fungal vaccines which contain $\beta$-glucans merits further study.

The chaperone protein calnexin contains a 13-amino acid sequence which is highly conserved among fungi of the Ascomycota, a phylum that contains many medically important fungi including Aspergillus and the endemic dimorphic fungi. Vaccine delivery of calnexin in glucan particles conferred immunity to lethal challenge with multiple ascomycetes via expansion of antigen-specific CD4 ${ }^{+} \mathrm{T}_{\text {cells }}{ }^{33}$. These results suggest a strategy whereby $\mathrm{T}$ or $\mathrm{B}$ cell epitopes common to multiple species of fungi could be identified and combined to yield panfungal vaccines.

\section{CONCLUSIONS}

Remarkable progress has been made towards the development of fungal vaccines for use in humans. In animal studies, protection against all the major medically important mycoses has been achieved using a variety of vaccine designs ranging from subunit formulations to live attenuated fungi. Superior efficacy has been demonstrated using novel adjuvants and delivery systems aimed at stimulating arms of the immune system critical for control of fungal invasion. Three vaccines have undergone human trials demonstrating the feasibility of performing clinical trials targeting at risk populations. While many scientific and logistical obstacles remain, there is reason to be optimistic that clinically approved fungal vaccines will be forthcoming. 
Received: 29 November 2020; Accepted: 27 January 2021; Published online: 03 March 2021

\section{REFERENCES}

1. Vallabhaneni, S., Mody, R. K., Walker, T. \& Chiller, T. The global burden of fungal diseases. Infect. Dis. Clin. 30, 1-11 (2016).

2. Nami, S. et al. Fungal vaccines, mechanism of actions and immunology: a comprehensive review. Biomed. Pharmacother. 109, 333-344 (2019).

3. Brown, G. D. et al. Hidden killers: human fungal infections. Sci. Transl. Med. 4, 165rv113-165rv113 (2012).

4. Bongomin, F., Gago, S., Oladele, R. O. \& Denning, D. W. Global and multi-national prevalence of fungal diseases-estimate precision. J. Fungi 3, 57 (2017).

5. Benedict, K., Jackson, B. R., Chiller, T. \& Beer, K. D. Estimation of direct healthcare costs of fungal diseases in the United States. Clin. Infect. Dis. 68, 1791-1797 (2018).

6. Levitz, S. M. \& Golenbock, D. T. Beyond empiricism: informing vaccine development through innate immunity research. Cell 148, 1284-1292 (2012).

7. Levine, M. M. \& Sztein, M. B. Vaccine development strategies for improving immunization: the role of modern immunology. Nat. Immunol. 5, 460-464 (2004).

8. Ueno, K., Yanagihara, N., Shimizu, K. \& Miyazaki, Y. Vaccines and protective immune memory against cryptococcosis. Biol. Pharm. Bull. 43, 230-239 (2020).

9. Tso, G. H. W., Reales-Calderon, J. A. \& Pavelka, N. The elusive anti-Candida vaccine: lessons from the past and opportunities for the future. Front. Immunol. 9, 897-897 (2018)

10. Caballero Van Dyke, M. C. \& Wormley, F. L. Jr. A call to arms: quest for a Cryp tococcal vaccine. Trends Microbiol. 26, 436-446 (2018).

11. Levitz, S. M. Aspergillus vaccines: Hardly worth studying or worthy of hard study? Med. Mycol. 55, 103-108 (2017).

12. Ljungman, P. Vaccination of immunocompromised patients. Clin. Microbiol. Infect. 18, 93-99 (2012).

13. Mestas, J. \& Hughes, C. C. W. Of mice and not men: differences between mouse and human immunology. J. Immunol. 172, 2731-2738 (2004).

14. Hervé, C., Laupèze, B., Del Giudice, G., Didierlaurent, A. M. \& Tavares Da Silva, F. The how's and what's of vaccine reactogenicity. npj Vaccines 4, 39 (2019).

15. Burki, F. The eukaryotic tree of life from a global phylogenomic perspective. Cold Spring Harb. Perspect. Biol. 6, a016147-a016147 (2014).

16. Chang, C. C. \& Levitz, S. M. Fungal immunology in clinical practice: magical realism or practical reality? Med. Mycol. 57, S294-S306 (2019).

17. Garcia-Rubio, R., de Oliveira, H. C., Rivera, J. \& Trevijano-Contador, N. The fungal cell wall: Candida, Cryptococcus, and Aspergillus species. Front. Microbiol. https:// doi.org/10.3389/fmicb.2019.02993 (2020).

18. Levitz, S. M., Huang, H., Ostroff, G. R. \& Specht, C. A. Exploiting fungal cell wall components in vaccines. Semin. Immunopathol. 37, 199-207 (2015).

19. Drummond, R. A., Gaffen, S. L., Hise, A. G. \& Brown, G. D. Innate defense against fungal pathogens. Cold Spring Harb. Perspect. Med. 5, a019620 (2014).

20. Patin, E. C., Thompson, A. \& Orr, S. J. Pattern recognition receptors in fungal immunity. Semin. Cell Dev. Biol. 89, 24-33 (2019).

21. Gow, N. A. R., Latge, J. P. \& Munro, C. A. The fungal cell wall: structure, biosynthesis, and function. Microbiol. Spectr. https://doi.org/10.1128/microbiolspec. FUNK-0035-2016 (2017)

22. Casadevall, A. et al. The capsule of Cryptococcus neoformans. Virulence 10, 822-831 (2019).

23. Bielska, E. \& May, R. C. Extracellular vesicles of human pathogenic fungi. Curr. Opin. Microbiol. 52, 90-99 (2019).

24. Hopke, A., Brown, A. J. P., Hall, R. A. \& Wheeler, R. T. Dynamic fungal cell wall architecture in stress adaptation and immune evasion. Trends Microbiol. 26, 284-295 (2018).

25. Ueno, K. et al. A dendritic cell-based systemic vaccine induces long-lived lungresident memory Th17 cells and ameliorates pulmonary mycosis. Mucosal Immunol. 12, 265-276 (2019).

26. Lionakis, M. S. \& Levitz, S. M. Host control of fungal infections: lessons from basic studies and human cohorts. Annu. Rev. Immunol. 36, 157-191 (2018).

27. Portuondo, D. L., Ferreira, L. S., Urbaczek, A. C., Batista-Duharte, A. \& Carlos, I. Z. Adjuvants and delivery systems for antifungal vaccines: current state and future developments. Med. Mycol. 53, 69-89 (2015)

28. Huang, H., Ostroff, G. R., Lee, C. K., Specht, C. A. \& Levitz, S. M. Characterization and optimization of the glucan particle-based vaccine platform. Clin. Vaccin. Immunol. 20, 1585-1591 (2013).

29. Huang, $H$. et al. Relative contributions of dectin- 1 and complement to immune responses to particulate beta-glucans. J. Immunol. 189, 312-317 (2012).

30. Deepe, G. S. Jr. et al. Vaccination with an alkaline extract of Histoplasma capsulatum packaged in glucan particles confers protective immunity in mice. Vaccine 36, 3359-3367 (2018).
31. Hester, M. M. et al. Protection of mice against experimental cryptococcosis using glucan particle-based vaccines containing novel recombinant antigens. Vaccine 38, 620-626 (2020)

32. Specht, C. A. et al. Vaccination with recombinant Cryptococcus proteins in glucan particles protects mice against cryptococcosis in a manner dependent upon mouse strain and cryptococcal species. mBio 8, e01872-01817 (2017).

33. Wuthrich, M. et al. Calnexin induces expansion of antigen-specific CD4 ${ }^{+} \mathrm{T}$ cells that confer immunity to fungal ascomycetes via conserved epitopes. Cell Host Microbe 17, 452-465 (2015).

34. Hung, C. Y. et al. Glucan-chitin particles enhance Th17 response and improve protective efficacy of a multivalent antigen ( $\mathrm{rCpa} 1$ ) against pulmonary Coccidioides posadasii infection. Infect. Immun. https://doi.org/10.1128/IAI.00070-18 (2018).

35. Herwald, S. E. \& Kumamoto, C. A. Candida albicans niche specialization: features that distinguish biofilm cells from commensal cells. Curr. Fungal Infect. Rep. 8, 179-184 (2014)

36. Denning, D. W., Kneale, M., Sobel, J. D. \& Rautemaa-Richardson, R. Global burden of recurrent vulvovaginal candidiasis: a systematic review. Lancet Infect. Dis. 18, e339-e347 (2018).

37. Yang, Y. L. et al. Non-lethal Candida albicans cph1/cph1 efg1/efg 1 mutant partially protects mice from systemic infections by lethal wild-type cells. Mycol. Res. 113, 388-390 (2009).

38. De Bernardis, F., Graziani, S., Tirelli, F. \& Antonopoulou, S. Candida vaginitis: virulence, host response and vaccine prospects. Med. Mycol. 56, S26-S31 (2018).

39. Schmidt, C. S. et al. NDV-3, a recombinant alum-adjuvanted vaccine for Candida and Staphylococcus aureus, is safe and immunogenic in healthy adults. Vaccine 30, 7594-7600 (2012).

40. Vargas, G. et al. Protective effect of fungal extracellular vesicles against murine candidiasis. Cell Microbiol. 22, e13238 (2020).

41. Xin, H., Dziadek, S., Bundle, D. R. \& Cutler, J. E. Synthetic glycopeptide vaccines combining beta-mannan and peptide epitopes induce protection against candidiasis. Proc. Natl Acad. Sci. USA 105, 13526-13531 (2008).

42. De Bernardis, F. et al. A virosomal vaccine against candidal vaginitis: immunogenicity, efficacy and safety profile in animal models. Vaccine 30, 4490-4498 (2012).

43. Edwards, J. E. Jr. et al. A fungal immunotherapeutic vaccine (NDV-3a) for treatment of recurrent vulvovaginal candidiasis-a phase 2 randomized, doubleblind, placebo-controlled trial. Clin. Infect. Dis. 66, 1928-1936 (2018).

44. Casadevall, A. \& Pirofski, L.-A. A therapeutic vaccine for recurrent vulvovaginal candidiasis. Clin. Infect. Dis. 66, 1937-1939 (2018).

45. Cassone, A. Development of vaccines for Candida albicans: fighting a skilled transformer. Nat. Rev. Microbiol. 11, 884-891 (2013).

46. Tarang, S. et al. In silico design of a multivalent vaccine against Candida albicans. Sci. Rep. 10, 1066 (2020).

47. Rajasingham, R. et al. Global burden of disease of HIV-associated cryptococcal meningitis: an updated analysis. Lancet Infect. Dis. 17, 873-881 (2017).

48. Devi, S. J. N. Preclinical efficacy of a glucuronoxylomannan-tetanus toxoid conjugate vaccine of Cryptococcus neoformans in a murine model. Vaccine 14 841-844 (1996).

49. Datta, K., Lees, A. \& Pirofski, L.-a. Therapeutic efficacy of a conjugate vaccine containing a peptide mimotope of cryptococcal capsular polysaccharide glucuronoxylomannan. Clin. Vaccin. Immunol. 15, 1176-1187 (2008).

50. Mansour, M. K., Yauch, L. E., Rottman, J. B. \& Levitz, S. M. Protective efficacy of antigenic fractions in mouse models of cryptococcosis. Infect. Immun. $\mathbf{7 2}$ 1746-1754 (2004).

51. Chaturvedi, A. K., Weintraub, S. T., Lopez-Ribot, J. L. \& Wormley, F. L. Jr. Identification and characterization of Cryptococcus neoformans protein fractions that induce protective immune responses. Proteomics 13, 3429-3441 (2013).

52. Specht, C. A. et al. Protection against experimental cryptococcosis following vaccination with glucan particles containing cryptococcus alkaline extracts. $\mathrm{mBio}$ 6, e01905-e01915 (2015).

53. Chaturvedi, A. K. et al. Vaccine-mediated immune responses to experimental pulmonary Cryptococcus gattii infection in mice. PLoS ONE 9, e104316 (2014).

54. Rizzo, J. et al. New insights into Cryptococcus extracellular vesicles suggest a new structural model and an antifungal vaccine strategy. Preprint at bioRxiv https:// doi.org/10.1101/2020.08.17.253716 (2020).

55. Hester, M. M. et al. Protection of mice against experimental cryptococcosis using glucan particle-based vaccines containing novel recombinant antigens. Vaccine https://doi.org/10.1016/j.vaccine.2019.10.051 (2019).

56. Upadhya, R. et al. Induction of protective immunity to cryptococcal infection in mice by a heat-killed, chitosan-deficient strain of Cryptococcus neoformans. mBio 7, e00547-00516 (2016).

57. Zhai, B. et al. Development of protective inflammation and cell-mediated immunity against Cryptococcus neoformans after exposure to hyphal mutants. mBio 6, e01433-01415 (2015). 
58. Rella, A. et al. Role of sterylglucosidase 1 (Sgl1) on the pathogenicity of Cryptococcus neoformans: potential applications for vaccine development. Front. Microbiol. https://doi.org/10.3389/fmicb.2015.00836 (2015).

59. Wang, Y., Wang, K., Masso-Silva, J. A., Rivera, A. \& Xue, C. A heat-killed Cryptococcus mutant strain induces host protection against multiple invasive mycoses in a murine vaccine model. mBio 10, e02145-02119 (2019).

60. Wormley, F. L., Perfect, J. R., Steele, C. \& Cox, G. M. Protection against cryptococcosis by using a murine gamma interferon-producing Cryptococcus neoformans strain. Infect. Immun. 75, 1453 (2007).

61. Hole, C. R. et al. Induction of memory-like dendritic cell responses in vivo. Nat. Commun. 10, 2955 (2019).

62. Angkasekwinai, P. et al. Cryptococcus gattii infection dampens Th1 and Th17 responses by attenuating dendritic cell function and pulmonary chemokine expression in the immunocompetent hosts. Infect. Immun. 82, 3880-3890 (2014).

63. van de Veerdonk, F. L., Gresnigt, M. S., Romani, L., Netea, M. G. \& Latgé, J.-P. Aspergillus fumigatus morphology and dynamic host interactions. Nat. Rev. Microbiol. 15, 661-674 (2017).

64. Vahsen, T. et al. Cellular and molecular insights on the regulation of innate immune responses to experimental aspergillosis in chicken and turkey poults. Med. Mycol. https://doi.org/10.1093/mmy/myaa069 (2020).

65. Levitz, S. M. Aspergillus vaccines: Hardly worth studying or worthy of hard study? Med. Mycol. 55, 103-108 (2017).

66. Bozza, S. et al. A dendritic cell vaccine against invasive aspergillosis in allogeneic hematopoietic transplantation. Blood 102, 3807-3814 (2003).

67. Perruccio, K. et al. Transferring functional immune responses to pathogens after haploidentical hematopoietic transplantation. Blood 106, 4397-4406 (2005).

68. Stuehler, C. et al. Multispecific aspergillus T cells selected by CD137 or CD154 induce protective immune responses against the most relevant mold infections. J. Infect. Dis. 211, 1251-1261 (2015).

69. Kumaresan, P. R. et al. Bioengineering T cells to target carbohydrate to treat opportunistic fungal infection. Proc. Natl Acad. Sci. USA 111, 10660-10665 (2014).

70. Chaturvedi, A. K., Kavishwar, A., Shiva Keshava, G. B. \& Shukla, P. K. Monoclonal immunoglobulin G1 Directed against Aspergillus fumigatus cell wall glycoprotein Protects against experimental murine aspergillosis. Clin. Diagn. Lab. Immunol. 12, 1063-1068 (2005).

71. Wharton, R. E., Stefanov, E. K., King, R. G. \& Kearney, J. F. Antibodies generated against streptococci protect in a mouse model of disseminated aspergillosis. J. Immunol. 194, 4387 (2015).

72. Klein, B. S. \& Tebbets, B. Dimorphism and virulence in fungi. Curr. Opin. Microbiol. 10, 314-319 (2007).

73. Pappagianis, D. Evaluation of the protective efficacy of the killed Coccidioides immitis spherule vaccine in humans. The Valley Fever Vaccine Study Group. Am. Rev. Respir. Dis. 148, 656-660 (1993).

74. Wüthrich, M. et al. Safety, tolerability, and immunogenicity of a recombinant, genetically engineered, live-attenuated vaccine against canine blastomycosis. Clin. Vaccin. Immunol. 18, 783-789 (2011)

75. Cleare, L. G., Zamith-Miranda, D. \& Nosanchuk, J. D. Heat shock proteins in Histoplasma and Paracoccidioides. Clin. Vaccin. Immunol. 24, e00217-00217 (2017).

76. de Bastos Ascenco Soares, R., Gomez, F. J., de Almeida Soares, C. M. \& Deepe, G. S. $J$ J. Vaccination with heat shock protein 60 induces a protective immune response against experimental Paracoccidioides brasiliensis pulmonary infection. Infect. Immun. 76, 4214-4221 (2008).

77. Van Dyke, M. C. C., Thompson, G. R., Galgiani, J. N. \& Barker, B. M. The rise of Coccidioides: forces against the dust devil unleashed. Front. Immunol. 10, 2188 (2019).

78. Garcia-Carnero, L. C., Perez-Garcia, L. A., Martinez-Alvarez, J. A., Reyes-Martinez, J. E. \& Mora-Montes, H. M. Current trends to control fungal pathogens: exploiting our knowledge in the host-pathogen interaction. Infect. Drug Resist. 11, 903-913 (2018).

79. Wong, L. P., Woo, P. C., Wu, A. Y. \& Yuen, K. Y. DNA immunization using a secreted cell wall antigen $\mathrm{Mp} 1 \mathrm{p}$ is protective against Penicillium marneffei infection. Vaccine 20, 2878-2886 (2002).
80. Tarcha, E. J., Basrur, V., Hung, C. Y., Gardner, M. J. \& Cole, G. T. Multivalent recombinant protein vaccine against coccidioidomycosis. Infect. Immun. 74, 5802-5813 (2006)

81. Hurtgen, B. J., Hung, C. Y., Ostroff, G. R., Levitz, S. M. \& Cole, G. T. Construction and evaluation of a novel recombinant $T$ cell epitope-based vaccine against coccidioidomycosis. Infect. Immun. 80, 3960-3974 (2012).

82. Rachini, A. et al. An anti-beta-glucan monoclonal antibody inhibits growth and capsule formation of Cryptococcus neoformans in vitro and exerts therapeutic, anticryptococcal activity in vivo. Infect. Immun. 75, 5085-5094 (2007).

83. Torosantucci, A. et al. A novel glyco-conjugate vaccine against fungal pathogens. J. Exp. Med. 202, 597-606 (2005).

84. Bromuro, C. et al. Beta-glucan-CRM197 conjugates as candidates antifungal vaccines. Vaccine 28, 2615-2623 (2010).

85. Clemons, K. V. et al. Whole glucan particles as a vaccine against murine aspergillosis. J. Med. Microbiol. 63, 1750-1759 (2014).

86. Liu, M. et al. Immune responses induced by heat killed Saccharomyces cerevisiae: a vaccine against fungal infection. Vaccine 29, 1745-1753 (2011).

87. Netea, M. G. et al. Defining trained immunity and its role in health and disease. Nat. Rev. Immunol. 20, 375-388 (2020).

\section{ACKNOWLEDGEMENTS}

Research in the authors' lab is supported by National Institutes of Health grants Al025780, Al139615, Al125045 and contract 75N93019C0004.

\section{AUTHOR CONTRIBUTIONS}

L.V.N.O., R.W., C.A.S., and S.M.L. contributed to the design, writing, and critical review of the paper.

\section{COMPETING INTERESTS}

The authors declare no competing interests.

\section{ADDITIONAL INFORMATION}

Correspondence and requests for materials should be addressed to S.M.L.

Reprints and permission information is available at http://www.nature.com/ reprints

Publisher's note Springer Nature remains neutral with regard to jurisdictional claims in published maps and institutional affiliations.

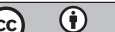

Open Access This article is licensed under a Creative Commons Attribution 4.0 International License, which permits use, sharing, adaptation, distribution and reproduction in any medium or format, as long as you give appropriate credit to the original author(s) and the source, provide a link to the Creative Commons license, and indicate if changes were made. The images or other third party material in this article are included in the article's Creative Commons license, unless indicated otherwise in a credit line to the material. If material is not included in the article's Creative Commons license and your intended use is not permitted by statutory regulation or exceeds the permitted use, you will need to obtain permission directly from the copyright holder. To view a copy of this license, visit http://creativecommons. org/licenses/by/4.0/.

(c) The Author(s) 2021 